\title{
PATHOLOGICAL LESIONS AND INCIDENCE OF FIBRINOUS PLEUROPNEUMONIA IN IMPORTED BEEF CATTLE SLAUGHTERED AT ABU-SIMBEL CITY - ASWAN GOVERNORATE
}

\author{
MOHAMED.G. HAMED ${ }^{1}$; FATMA ABO ZAKAIB ALI ${ }^{1}$; A.Z. MAHMOUD ${ }^{2}$ and \\ SARY KH.ABD-ELGHAFFAR ${ }^{2}$ \\ ${ }^{1}$ Department of Pathology and Clinical Pathology, Faculty of Veterinary Medicine, \\ Sohag University, Sohag 82524, Egypt. \\ ${ }^{2}$ Department of Pathology and Clinical Pathology, Faculty of Veterinary Medicine, \\ Assiut University, Assiut, Egypt.
}

Received: 28 August 2018; Accepted: 18 September 2018

\begin{abstract}
The current study was conducted on 110 lung samples from 2 - 3 years old imported beef cattle slaughtered at the Middle East abattoirs of Abu-Simbel city -Aswan Governorate- Egypt, in the period from July 2017 to March 2018. The aim of the present work was to characterize and detect the incidence rate of the pulmonary affections. During the postmortem examination, the pulmonary affections were recorded grossly and specimens were taken for histopathological examinations. The histopathological examinations revealed that 36 samples $(32.7 \%)$ showed fibrinous pleuropneumonia. According to the characteristic features of lesions in the microscopical studies, we grouped them into (a) Acute fibrinous pleuropneumonia in 31cases (28.1\%) and (b) Organized fibrinous pleuropneumonia in 5 cases $(4.5 \%)$. The causes of these affection and their importance were discussed.
\end{abstract}

Key words: Lung, Fibrinous, Pleuropneumonia, Bronchopneumonia.

\section{INTRODUCTION}

Pneumonia is defined as the inflammation of pulmonary parenchyma and it is usually accompanied by inflammation of the bronchioles (Bronchopneumonia) and/or by pleurisy (pleuropneumonia) (Blood et al., 1983). Cattle with fibrinous pleuropneumonia had grossly bilateral fibrinous pleuritis with either removable sheets of fibrin or firmly attached strands and networks of fibrin on the visceral and parietal surfaces. On cut section the most prominent characteristic feature of the fibrinous pleuropneumonia is the marbled appearance which resulted from the varying degrees of red to gray hepatization with distension of the interlobular septa and interstitium surrounding the vessels and airways with a yellowish serofibrinous exudate. (Kumar et al., 2006 and Lopez, 2012).

Fibrinous pleuropneumonia is characterized by congestion and consolidation of lungs and is usually accompanied by pleuritis. (Chauhan, 2010). The pulmonary lesions is formed in a similar way

Corresponding author: Dr. MOHAMED.G. HAMED

E-mail address: mohamed.gamal@vet.sohag.edu.eg

Present address: Department of Pathology and Clinical Pathology, Faculty of Veterinary Medicine, Sohag University, Sohag 82524, Egypt. regardless of the type of etiological agent. It include various stages of congestion, red hepatization, grey hepatization then resolution. (Chauhan, 2010). Fibrinous pleuropneumonias was classified previously into acute fibrinous pleuropneumonia and organized fibrinous pleuropneumonia. (Schiefer et al., 1978 and Haridy, 2003). The latter stages of fibrinous pleuropneumonia representing the organized fibrinous pleuropneumonia type (Jensen et al., 1976). Morever Gibbs et al. (1983) stated that, the pleural surface was bulged and thus produced mild nodulation. Later on, areas of fibrinous pleuropneumonia were often confined by fibrous tissue forming nodules.

In cattle, fibrinous pneumonia is characterized by the accumulation of exudates in the bronchiolar and alveolar spaces. Organization of this material is one of the most distinguished phenomenon of the pneumonic lesion in cattle especially when died during severe $M$. haemolytica infection. (Lopez, 2012 and Azizi et al., 2013).

Concerning the fibrinous pleuritis in cases of fibrinous pleuropneumonia, Siqueira et al. (2018) stated that the pleura had marked edema, fibrin deposition and moderately severe infiltration of neutrophils and macrophages, Trichard et al. (1989) 
mentioned that the sequestra were the most characteristic feature of contagious bovine pleuropneumonia (CBPP). The sequestra varied in size from $15 \mathrm{~mm}$ to very large, involving more than one lobe of a lung. The sequestra were often surrounded by a thin irregular fibrous capsule and contained reddish -pink to yellowish - gray necrotic tissue. Histologically, part of a lobule or a lobule or multiple lobules and their intervening septa became necrotic. Vasculitis and thrombosis of the intralobular and interlobular arteries were noticed in some of the necrotic areas. Trichard et al. (1989).

Previous studies recorded a strong correlation between bacteriological and histopathological findings in bovine fibrinous pneumonia (Schiefer $e t$ al., 1978), as Bovine respiratory disease (BRD) including shipping fever, which is indicated by fibrinous pneumonia or pleuritis is usually caused by Mannheimia haemolytica (Singh et al., 2011) and Pasteurella multocida (Welsh et al., 2004 and Caswell and Williams, 2016), the above mentioned micro-organisms are the most common bacteria isolating from animals with BRD (Singh et al., 2011). In addition, M. haemolytica as well as Mycoplasma mycoides, are the micro-organisms frequently related to fibrinous pathological condition (Jubb et al., 2007). Hemophilus somnus was recorded with either P. hemolytica or P. multocida in association or with other bacterial microbe like Bacillus spp, staph. aureus or E.coli as well (Schiefer et al., 1978).

\section{MATERIALS AND METHODS}

\section{Animals}

Beef cattle of sudanese-origin aged from $2-3$ years were kept in quarantine for 21 days under observation and supervision of Egyptian Quarantine Veterinarians in the Sudanese city of Wadi Half (bordering Egypt). Afterwards, cattle are shipped down the Nile to the city of Abu Simbel, Aswan Governorate where they are slaughtered.

\section{Specimen collection}

Regular visits were done to the Middle East Slaughterhouse during the period from July 2017 to March 2018. Routine postmortem examination of 1450 slaughtered beef cattle was carried out with particular attention to the pulmonary affections. Tissue specimens from lungs of 110 animals grossly showing pathological changes were collected and all lesions are imaged by a digital camera.

\section{Histopathological examinations}

Specimens from different lesions of lungs were fixed in $10 \%$ neutral buffered formalin. Preparation of tissue for histopathological examination was carried out according to the method described by (Bancroft et al., 1996).

\section{RESULTS}

\section{Pathological examination:}

Out of 110 pneumonic lung cases, pleuropneumonia was observed in $36 \quad(32.7 \%)$ cases. Histopathologically, these lesions were grouped them into: (a) Acute fibrinous pleuropneumonia in $31(28.1 \%)$ cases and (b) Organized fibrinous pleuropneumonia in $5(4.5 \%)$ cases.

\section{a. Acute fibrinous pleuropneumonia:}

The number of cases, which showed acute fibrinous pleuropneumonia, was 31 cases.

\section{Gross examination}

Our gross examination during lungs necropsy revealed marked lung enlargement, non-collapsed, firm, and covered diffusely with large amounts of a yellowish fibrillary material (fibrin). The parietal and visceral pleura were thickened. There were large amounts of fibrinous exudate above the pleura leaded to adhesions between the visceral and parietal pleural layers (Fig 1, a) as well as adherence to the chest wall. The thoracic cavity contained a yellowish serous fluid with a small amount of fibrin casts. In the cut sections we observed the interlobular septa are widened with serofibrinous exudate, lymphatic vessels were dilated and there were multiple foci of hepatization (red or gray) according to the age of the lesion, giving the lung marbling or mosaic appearance (Fig 1, b).

\section{Microscopical examination}

The histopathological examination recorded that, the pleura was extended by a diffuse inflammatory infiltrate constituted from degenerate neutrophils combined with a deposition of a fibrillary eosinophilic material (fibrin) (Fig 2, a). The interlobular septa were markedly expanded with fibrinous exudate, which formed by fibrin network, macrophages, neutrophils, and eosinophilic faint pink serous exudate (Fig 2, b). The bronchiolar epithelium was showed degenerative changes and the bronchiolar lumen was filled with fibrinous exudate (Fig 2, c). The alveolar lumens were dilated and filled with fibrinous exudate (Fig 2, d). The fibrinous exudate was composed of fibrin network, macrophages, some neutrophils and erythrocytes.

\section{b. Organized fibrinous pleuropneumonia}

The number of cases which showed organized fibrinous pleuropneumonia, were 5 cases.

\section{Gross observation}

Marked thickening in the pleural tissue. Thickening is due to organizations of fibrinous exudate, which turned into fibro-vascular tissue. Organization was manifested by presence of fibrous bands connecting the parietal and visceral pleural layers (Fig 3, a). In some chronic cases there were large area of necrosis which surrounded by fibrous capsule occupying 
large area of lung lobules (Fig 3, b) (sequestrum), in cut section alternating areas of red, gray hepatization, coagulative necrosis and thickening of interlobular septa were observed.

\section{Microscopical examination}

The main lung changes were in the presence of proliferating connective tissue replacing the destructed alveolar tissue besides existence of remnant of fibrinous exudation (Fig 4, a). The alveolar walls were thickened due to development of dense fibrous connective tissue. The thickened alveolar walls were distorted giving rise to atelectasis of the some alveoli (slit-like appearance) (Fig 4, b). The interlobular septa were greatly thickened due to presence of granulation tissue. The granulation tissue was formed of collagen fibrils, fibroblasts, lymphocytes, macrophages and newly formed blood vessels, some blood vessels showed fibrinoid degeneration of thier wall.

Other lung lesions were recorded in the imported beef cattle and diagnosed and will be published in the further work.
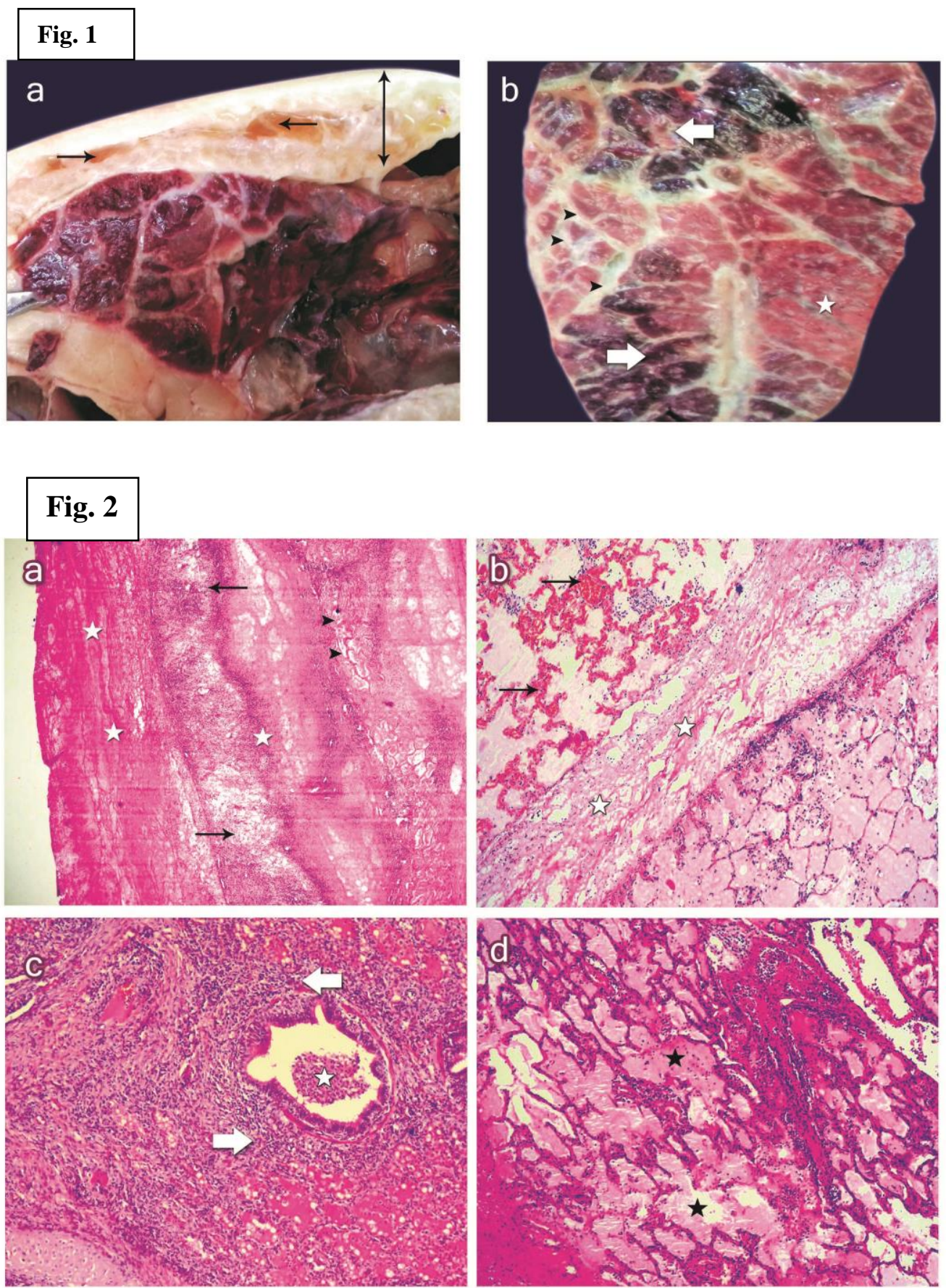

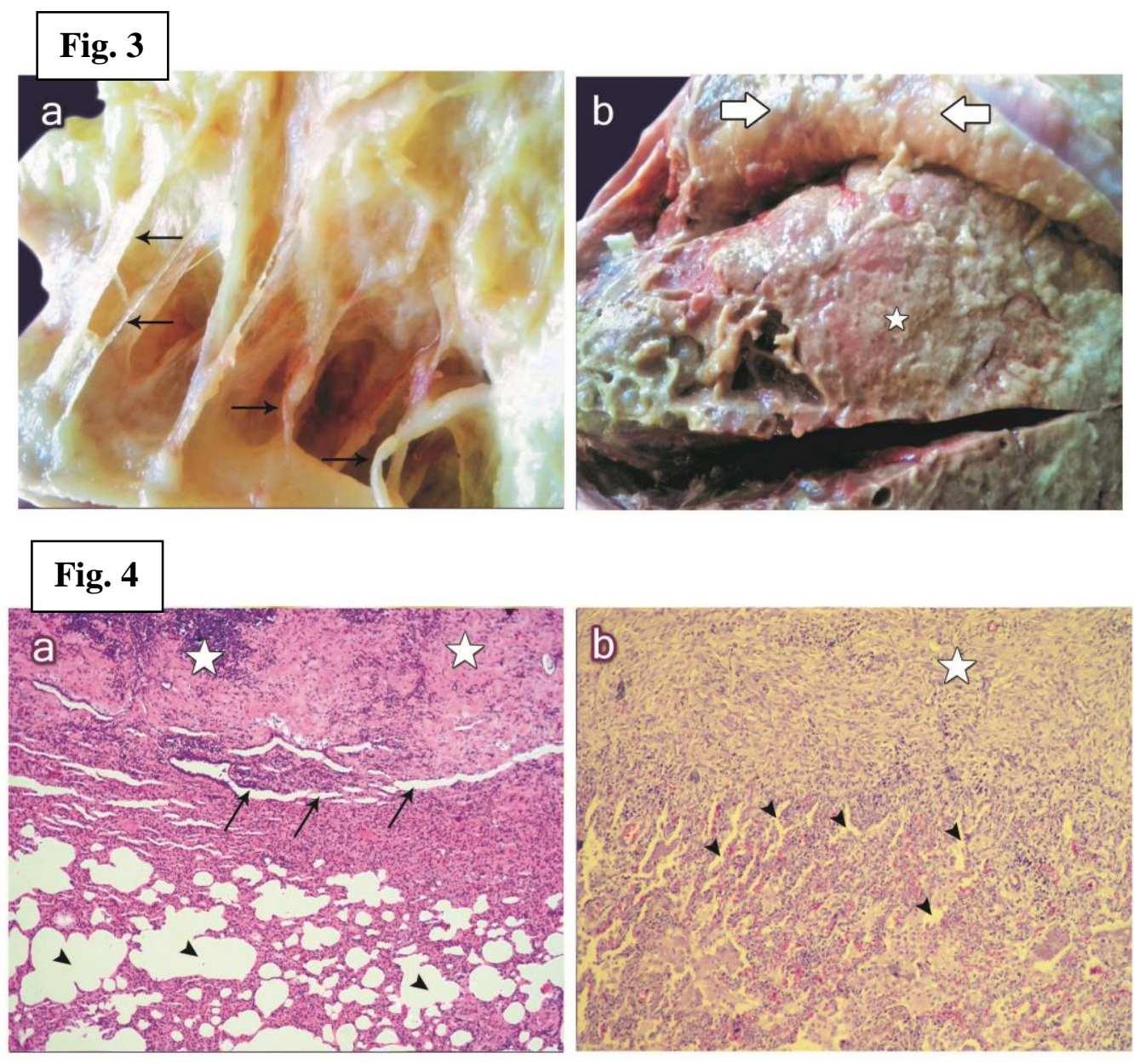

\section{LEGEND OF FIGURES}

Figure 1: (a) Lung showing large amounts of fibrinous exudate above the pleura (arrows), adhesions of the thickened visceral and parietal pleura (double arrows) and thickening of interlobular septa. (b) Cut section showing a small portion of the healthy lung (star), while the remaining surface showed red to gray hepatization of lobules (white arrows) and thickening of interlobular septa (arrows head).

Figure 2: (a) Lung showing thickened pleura with deposited fibrin (stars) and leucocytic cellular infiltration (arrows). The alveoli as well contained fibrin threads mixed with red blood cells and leucocytes (arrows head) (Hx \& E.X 4). (b): The interlobular septa showing expansion (Stars) with fibrin network, macrophages as well as neutrophils and congestion of inter alveolar capillaries (arrows) (Hx\&E, X10), (c): Lung showing moderate degenerative changes of the bronchiolar epithelium, fibrinopurulent exudate in the lumen (star) and peribronchiolar leucocytic infilterations (arrows) (Hx\&E, X10). (d): Lung showing fibrino-cellular exudate in the alveolar luminae (stars) $(\mathrm{Hx} \& \mathrm{E}$, $\mathrm{X} 10)$.

Figure 3: (a) the parietal and visceral pleura were thickened and organizations of fibrinous exudate into fibrous bands (arrows) leaded to adhesions connect the thickened visceral and parietal pleura (b): Pneumonic lung showing large sequestrum consisting of necrotic parenchyma (star) surrounded by a thick fibrotic capsule (arrows).

Figure 4: (a) Pneumonic lung showing organized fibrinous pleuritis (star), atelectasis (arrows) and some compensatory alveolar emphysema (arrows head) (Hx\&E, X10). (b): Pleura showing great thickening due to organization with collagenous connective tissue (star) and marked neovascularization and fibroblasts proliferation (arrows head) (Hx\&E X10).

\section{DISCUSSION}

In the present study, 36 cases out of 110 lungs from 1450 slaughtered imported beef cattle showed fibrinous pleuropneumonia. According to the microscopic characteristic features of this lesion two categories were observed: (a) Acute fibrinous pleuropneumonia in 31 cases $(28.1 \%)$ and (b) organized fibrinous pleuropneumonia in 5 cases (4.5 $\%)$. This was nearly similar to the incidence recorded by (Schiefer et al., 1978 and Haridy, 2003). 
Our data revealed that, acute fibrinous pleuropneumonia in which their gross appearance surfaced great thickened parietal and visceral pleura in addition it was covered with abundant amounts of a yellowish fibrillary material (fibrin) diffusely. such copious fibrinous exudate above the pleura leaded to adhesion between visceral and parietal pleura as well as its adherence to the chest wall. The lungs were enlarged, non-collapsed, firm, hepatized and exhibited interlobular septa that were thickened with a gelatinous material (oedema). This picture was previously described by (Schiefer et al., 1978; Kumar et al., 2006 and Lopez, 2012).

Here in the present study, widening of interlobular septa with serofibrinous exudate, dilatation of lymphatic vessels and presence of multiple foci of hepatizations were observed. According to the age of the lesion, the alternating appearance of red and gray hepatizations gave the marbling or mosaic appearance. These observations are consistent with others observations (Schiefer et al., 1978; Kumar et al., 2006 and Lopez, 2012).

Histopathologically, the parietal and visceral pleura were expanded by a diffuse inflammatory infiltrate composed of degenerate neutrophils together with deposition of a fibrillary eosinophilic material (fibrin). The alveolar luminae were dilated and filled with fibrinous exudate which appeared as a fibrin network engaged with macrophages, neutrophils and erythrocytes. The interlobular septa was markedly expanded with fibrinous exudate, which formed of fibrin network, macrophages, neutrophils and eosinophilic faint pink serous exudate. This picture was previously described by Haridy (2003); Jubb et al. (2007); Lopez (2012) and Azizi et al. (2013). In the present study, organized fibrinous pleuropneumonia was recorded in 5 cases with an incidence of $4.5 \%$. This was grossly, manifested by presence of fibrous bands in the lobular pattern which somewhat compressed lung alveoli. In addition,the pleura was highly thickened as a result of organizations of fibrinous exudate which converted into fibro-vascular tissue. In more chronic cases, massive necrosis occupying large area of lung lobules (sequestrum) and surrounded by fibrous capsule was observed. Morever variable alternation in the lung tissue in the form of red, gray hepatization, coagulative necrosis and thickening of interlobular septa had been detected. The same descriptions were reported by Schiefer et al. (1978); Gibbs et al. (1983); Trichard et al. (1989); and Lopez (2012). The microscopical finding of organized fibrinous pleuropneumonia in our results revealed that the alveolar walls were thickened due to presence of dense fibrous connective tissue. The thickened alveolar walls were distorted giving rise to atelectasis of the some alveoli (slit like appearance). The pleura and interlobular septa were greatly thickened due to presence of granulation tissue formed of collagen fibrils, fibroblasts, lymphocytes, macrophages and newly formed blood vessels. This picture was previously described by Schiefer et al. (1978) and Jubb et al. (2007). Many authors in the previous studies mentioned that the etiological prevalence of the fibrinous pleuropneumonia was attributable to Mannheimia hemolytica Schiefer et al. (1978); Singh et al. (2011); and Jubb et al. (2007), Mycoplasma mycoides subsp mycoides Scheneider et al. (1994); Schiefer et al. (1978) and Jubb et al. (2007), Pasteurella multocida Schiefer et al. (1978); Radostits et al. (2000); Welsh et al. (2004) and Siqueira et al. (2018).

\section{CONCLUSION}

High incidence of fibrinous pleuropneumonia was recorded during slaughtering imported beef cattle at Middle East abattoirs in Abu-Simbel city, Aswan Governorate- Egypt. The etiological agents of the fibrinous pleuropneumonia could be attributable to Mannheimia hemolytica, Mycoplasma mycoides subsp mycoides or Pasteurella multocida infections. The importations of animals in a live state increase the possibility of infections in our animals, so we advise to perform strict quarantine measures to these animals, however slaughtering it in the original country is better to decrease the possibility of diseases transmission.

\section{REFERENCES}

Azizi, S.; Farzad, S.K. and Ahmad, O. (2013): Pneumonia in slaughtered sheep in southwestern Iran: pathological characteristics and aerobic bacterial aetiology, Veterinaria Italiana, 49 (1), 109-118.

Bancroft, J.D. Stevens and Turner, D.R. (1996): Theory and Practice of Histological Tequniques. 4 th Ed. Pearson Professional limited. London, U.K.

Blood, D.C.; Radostits, O.M. and Henderson, J.A. (1983): Veterinary Medicine: A text book of disease of cattle, sheep, pigs, goats and horses. 6th ed, Pitman press. London. U.K.

Caswell, J.L. and Williams, K.J. (2016): Respiratory system. In: JUBB, KENNEDY, AND PALMER'S. Pathology of domestic animals. 6th ed. St. Louis, Missouri, Elsevier, p. 542546.

Chauhan, R.S. (2010): Text Book of Veterinary Pathology: Quick Review and Self Assessment. Ibdc publishers. pp. 171-188.

Gibbs, H.A.; Allan, E.M.; Wiseman, A. and Selman, I.E. (1983): Pneumonic pasteurellosis in housed, weaned, single suckled calves. Vet. Rec. 22: 87 
Haridy, M. (2003): pathological studies on lung affections in fattening calves Mvsc thesis, Assuit university, Assuit Egypt.

Jensen, R.; Pierson, R.E.; Braddy, P.M.; Saari, D.A.; Lauerman, L.H.; England, J.J.; Keyvanfar, H.; Collier, J.R.; Horton, D.P.; McChesney, A.E.; Abarham Benitez and Christie, R.M. (1976): Atypical interstitial pneumonia in yearling feedlot cattle. J. Am. Vet. Med. Assoc.169: 507.

Jubb, K.V.F.; Kennedy, P.C. and Palmer, N. (2007): Pathology of Domestic animals. 3rd ed. Vol. 2 Academic press, INC. (USA).

Kumar, H.; Sharma, S.; Mahajan, V.; Verma, S.; Arora, A.K.; Paviter Kaur and Sandhu, KS. (2006): Pathology and PCR based confirmation of Haemorrhagic Septicemia outbreaks on bovines. Indian Journal of Veterinary Pathology, 30(1): 5-8.

Lopez, A. (2012): Respiratory system, mediastinum, and pleurae. In: Zachary JF, McGavin MD, editors. Pathologic Basis of Veterinary Disease. 5th edition. St. Louis, Miss, USA: Mosby Elsevier; pp.458-538.

Radostits, OM.; Gary, CC.; Blood, DC. and Hinchcliff, $K W$. (2000): Veterinary Medicine, A text book of the Disease of Cattle, Sheep, Pigs, Goats and Horses (9 ed.). London: Harcourt Publishers Limited.

Schiefer, B.; Ward, G.E. and Moffatt, R.G. (1978): Correlation of microbiological and histological findings in bovine fibrinous pneumonia. Vet. Path.15: 313-21

Schneider, H.P.; van der Lugt, J.J. and Hubschle, O.J.B. (1994): Contagious bovine pleuropneumonia, in Infectious Diseases of Livestock, with Special Reference to Southern Africa. J.A.W.; Coetzer, G.R.; Thomson, and R. C. Tustin (ed.), Oxford University Press, Cape Town, South Africa. P. 1485-1494.

Singh, K. (2011): Mannheimia haemolytica: Bacterial-Host Interactions in Bovine Pneumonia. Vet. Path, v.48, n.2, p.338-348, 2011. doi: 10.1177/0300985810377182.

Siqueira F.M.; Matheus, V.B. and Lauren, S.M. (2018): Fibrinous pleuropneumonia caused by Pasteurella multocida associated with bovine lymphoma Ciência Rural, v.48, n.5.

Trichard, C.J.V.; Bassoon, P.A.; Lugt, J.J.; Van der and Jacobsz, E.P. (1989): An outbreak of contagious bovine pleuropneumonia in the Owambo Mangetti area of southwest Africa /Namibia: microbiological, immune fluorescent, pathological and serological findings. Onderstepoort J. Vet. Res. 56: 27784

Welsh, R.D. (2017): Isolation and antimicrobial susceptibilities of bacterial pathogens from bovine pneumonia: 1994-2002. Journal of Veterinary Diagnostic Investigation, v.16, p.426-431, 2004. Available from: doi: $10.1177 / 104063870401600510$.

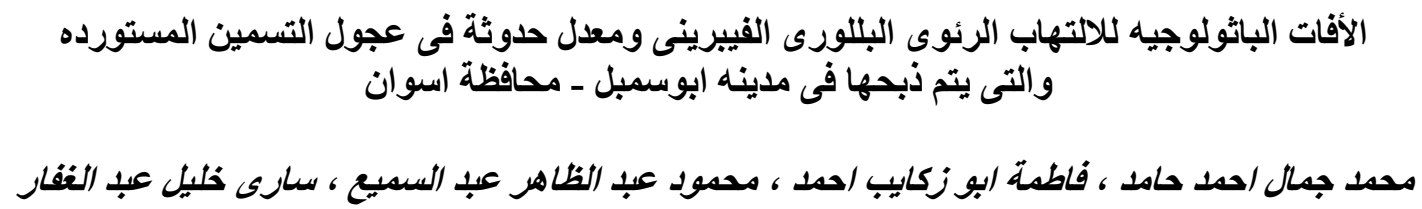

E-mail: mohamed.gamal@vet.sohag.edu.eg Assiut University web-site: www.aun.edu.eg

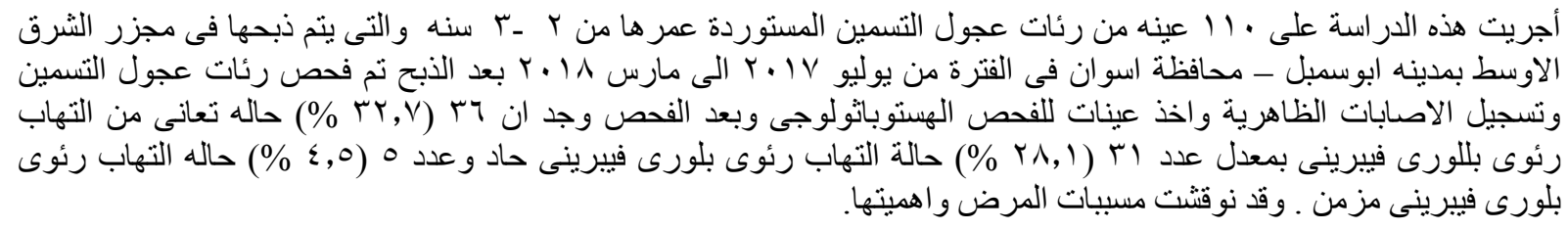

